\title{
MARTIAN WIND ACTIVITY DETECTED BY A SEISMOMETER AT VIKING LANDER 2 SITE
}

\author{
Yosio Nakamure
}

Geophysics Laboratory, Marine ScIence Institute, The University of Texas, Galveston, Texas

\begin{abstract}
The seismic 'background nolse' detected by the selsmometer on the Viking lander 2 has an extremely high correlation with the measured wind speed at the landing site. When displayed in a compressed form, the nearly continuous seismic data clearly exhibit the diurnal as well as seasonal variations of the Martian wind activity. A preliminary spectral analysis of the long-term variation of the background noise indicates persistent spectral peaks at pertods near $1.5,3,7$ and 10-20 sols for the first 560 sols ( 0.84 Martian year) of observation.
\end{abstract}

The Viking lander 2 selsmometer [Anderson et al., 1977], being located on top of the lander, is extremely sensitive to Martian winds. Thus handicapped in detectir:g Martian seismic events, it can provide a recorc of Martian wind activity. The Viking seismometer, in a sense, is a better detector of Martian wind activity than the windspeed detector used for the Viking meteorology experiment. Unlike the wind-speed detector, which measures instantaneous wind speed at widely spaced time intervals, the seismometer continuously samples the wind-induced lander vibration. The selsmometer output thus well compliments the meteorology data. Here we present some pertinent selsmic data and results of a preliminary spectral analysis of the data.

\section{Wind Speed/Seismic Noise Correlation}

The wind blowing on the lander causes it to vibrate, and this vibration, in turn, is detected by the seismometer on the lander as increased 'background noise.' The correlation between the wind activity as measured by the meteorology experiment and the selsmic noise is clearly evident in the recorded data. A preliminary analysis has shown that the observed seismic amplitude is approximately proportional to the square of the wind speed, as expected for turbulent flow [Anderson et a1., 1977].

An example of the correlation between the wind speed and the seismic noise is shown in Fig. 1. The wind-speed data shown here are instantaneous values sampled at 1.2 second intervals, while the seismic data have been sampled at 8.25 millisecond intervals and averaged over every second.

Figure 2 shows the coherence and phase difference spectra of this pair of signals. The coherence between the selsmic amplitude and the squared wind speed is extremely high for frequencles below about $30 \mathrm{mHz}$ (period $30 \mathrm{sec}$ and longer), and signiflcant coherence is observed up to about $300 \mathrm{mHz}$ (down to $3 \mathrm{sec}$ period). The low

Copyright 1979 by the American Geophysical Union. coherence at high frequencies is partly due to the difference in data collection method: spot sampling for the wind data versus time averages for the seismic data.

The nearly zero phase spectrum indicates that the time lag between the wind-speed variation and the selsmic output is negligible, i.e., within the 0.8 second uncertainty of the relative timing of the two experiments. The seismometer, therefore, is responding almost immediately to the wind variations. This rules out the possibility that a detectable amount of seismic energy is transmitted through the ground from distant wind disturbances, leaving the direct action of the wind on the lander as the sole cause of the wind-induced seismic noise.

\section{Long-Term Varlation and Periodicity}

The Martian wind activity as detected by the Viking-2 seismometer displays relatively regular day-to-day variations as well as distinct variations with season. In order to demonstrate this long-term varlation, we have compressed the entire set of Viking-2 seismlc data by a factor of more than 5000 by averaging amplitudes over every 40 minutes, and plotted them in Fig. 3. Nolses generated by lander activities have been removed. The data covers about 84 percent of the 688.6-80l Martian year, roughly from midsummer to early summer in the northern hemisphere, the lander being located at $44^{\circ} \mathrm{N}$ latitude.

The summer time is relatively calm, while winter time is espectally windy. Besides the diumal pertodicity, which is clearly visible throughout the record, some additional. regularities can be ldentlfied; for instance, an extremely regular half-day periodicity from sol 280 to sol 312 and a 3-day periodicity around sol 220 through sol 250 and sol 330 through sol 360. The first interval is fust after winter solstice and covers the period of minimum temperatures and maximum pressures. A global dust storm also occurred in this period. The interval between sols 220 and 250 was a period of gradually decreasing temperature and relatively stable pressure. The last interval was a period of rapidiy increasing temperature and decreasing pressure.

We have computed power spectral density (PSD) estimates of this wind-induced noise to determine the periodicities of the wind activity. We first generated a basic data set consisting of about 80,000 ten-minute mean selsmic amplitude values covering the entire recording period. This set of data was then low-pass filtered using a 3-pole Butterworth filter with a cutoff frequency of $9.25 \mathrm{cycles} / \mathrm{sol}$, and was sampled at intervals of 

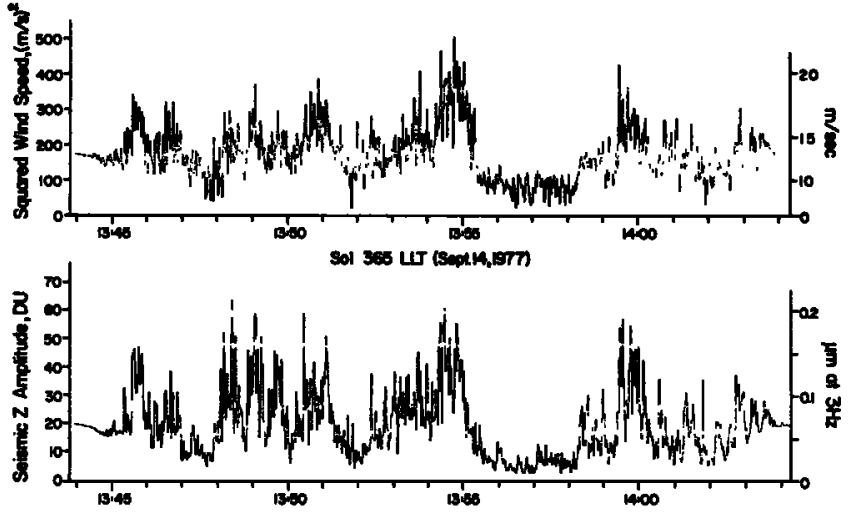

Fig. 1. Selsmic amplitude (horizontal $\mathrm{z}$ component) compared with squared wind speed for the data recorded on sol 365. The times are given in hours and minutes of the local lander time (LLT). The Martian day 1s approximately 24 hours and 40 minutes long.

40 minutes, generating a set of about 20,000 filtered seismic amplitude values. Finally, power spectral density estimates were computed for several different time intervals using the Cooley-Welch-Lewis method [Cooley et alo, 1967]. Figure 4 is the result for nearly the entire data set obtained by adding spectra of twenty overlapping 52-sol subsets of the data. The frequency resolution of the spectrum is 0.02 cycles/sol, and the variance of the spectral values is estlmated to be about 6 percent of the squared power density, giving a standard error of about $1.1 \mathrm{~dB}$.

The most prominent spectral peaks are those of the diurnal periodicity and 1 ts higher harmonics. Several additional peaks of significance, $1_{0} e_{\text {。 }}$ peaks at least several times the standard error above the background, are observed. Among them are the two spectral peaks at about 0.15 and 0.33 cycles/sol below the fundamental and each of the harmonics of the diurnal peaks. The general trend of the spectrum shows a decrease of spectral amplitude with increasing frequency at a rate of approximately $6 \mathrm{~dB} /$ octave. This rate is greater than that found earlier for higher frequencies [Anderson et al., 1977].

In order to see more detailed spectral features for perlods greater than 1 sol, we have computed a spectrum at a higher resolution at a cost of increased uncertainty in spectral values. To do this, the mean amplitude data were further low-pass filtered at a cutoff frequency of 1.54 cycles/sol, sampled at intervals of 4 hours, and the PSD estimates were computed for this set of data. The result is shown in Fig. 5. The resolution is increased to $0.004 \mathrm{cycles} / \mathrm{sol}$, but the estimated variance of the spectral values is increased to about 38 percent of the squared power density, giving a standard error of about $2.7 \mathrm{~dB}$.

All of the significant spectral peaks below 1 cycle/sol that are identifiable in Fig. 4 are more clearly defined in Fig. 5. They include peaks representing periodicities of $1.2,1.5,2$, 3 and 7 sols, and a broad peak covering 10 to 20 sols.

How these spectral peaks vary with season can be seen in Fig. 6, where the PSD estimates are plotted against time in the form of a spectrogram. The frequency resolution of this plot is the same as that of Fig. 4, but the standard error of the estimates is increased to about 2.3 $d B$ to obtain the finite time resolution of 130 sols. Some peaks, such as those at 3-sol and 7-so1 perlodicities, are consistently observed throughout the observation period, while others, such as those at 2.0 sols and $2.7 \mathrm{sols}$, are seasonal.

Prominent spectral peaks at frequencles up to 2 cycles/sol are listed in Table 1 .

\section{Discussion}

The results indicate that wind variations on Mars are extremely regular in the summer and winter. Winds are light in the summer and exhibit a strong diurnal periodicity, the strongest winds being in the early afternoon. Winds become stronger and more irregular in the auturn. High morning winds are common and a strong semidiurnal component appears. Average wind speeds increase in the winter and most days are windy. This is in contrast to the autumn when wind speeds can be high but many days are relatively calm. In all seasons nighttime conditions are usually very calm. The high wind season correlates with the duration of the global dust storm. The spring is characterized by very strong but variable wind activity. In this season strong winds sometimes occur throughout the night, and the spectra contain more strong components. These results are generally in agreement with those of the Viking meteorology experinent [Hess et al., 1977].

The most persistent spectral peaks, aside from the strong diurnal peak, occur at periods near $1.5,3,7$ and $10-20$ sols. This can be compared with periods of $3-3.5$ and $6-7$ sols found in the atmospheric pressure variations [Ryan et at., 1978]. In the winter-spring season additional
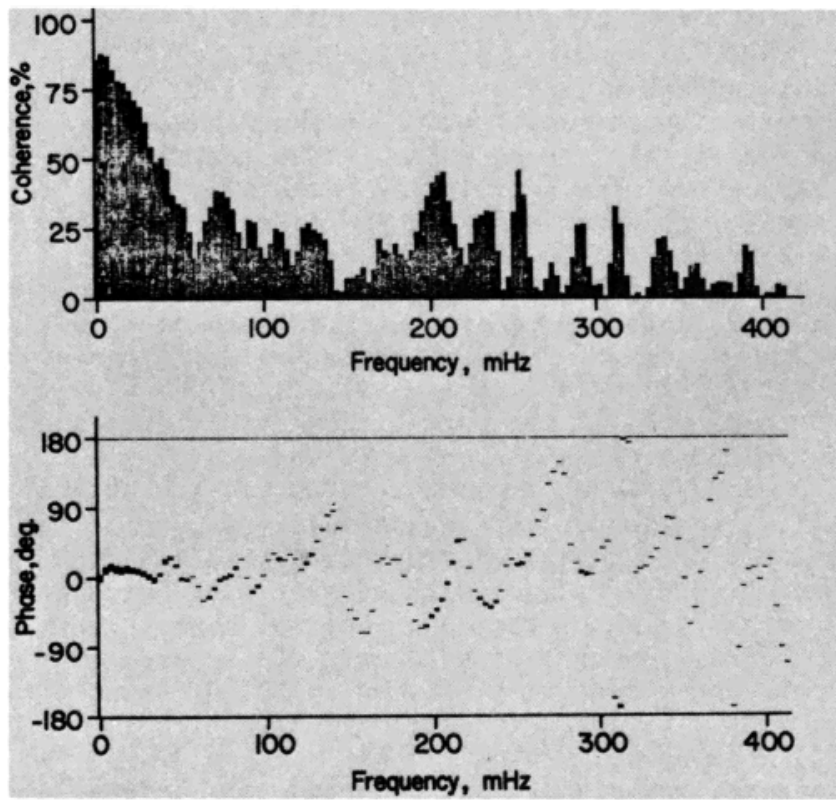

Fig. 2. Coherence and phase spectra between the seismic and wind-speed signals of $\mathrm{Fig} .1$. 


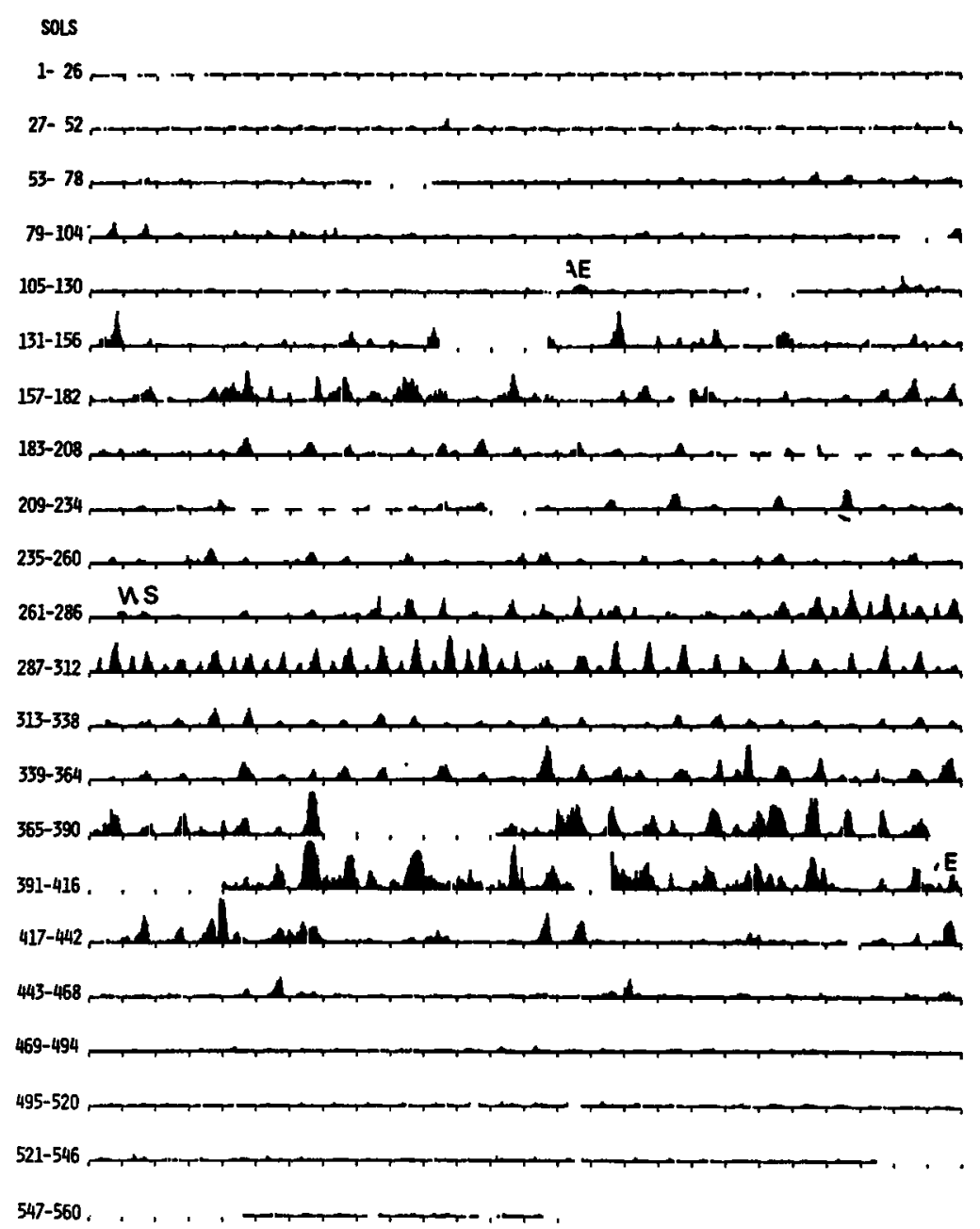

Fig. 3. Compressed plot of Viking lander 2 seismic signals. The data have been compressed by taking 40 minute averages of horizontal $\mathrm{Z}$ component amplitudes. Sol is the Mars day counted from the day of the spacecraft landing. The data roughly cover from September 4, 1976 to Apri1 2, 1978. Tick marks indicate local midnight. The trace spacing corresponds to an average amplitude of 120 digital units, which is roughly equivalent to a ground displacement of $0.3 \mu \mathrm{m}$ at $3 \mathrm{~Hz}$. $A E$, WS and $\mathrm{VE}$ indicate approximate dates of autumnal equinox, winter solstice and vernal equinox, respectively.

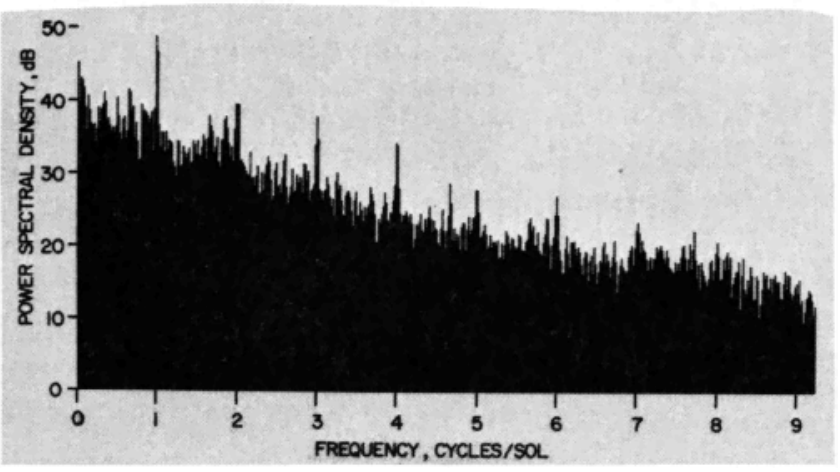

Fig. 4. Power spectral density estimate of selsmic horizontal $z$ component signals for the interval of sol 1 through 546. The estimated standard error is $1.1 \mathrm{~dB}$.

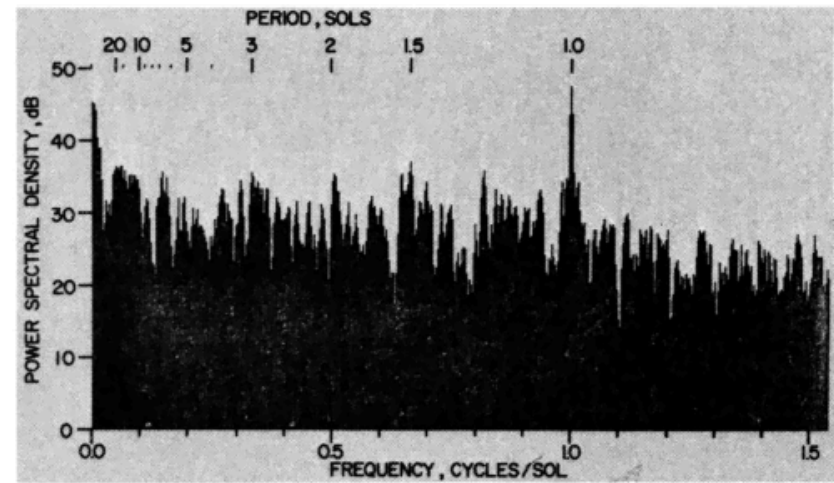

Fig. 5. Power spectral density estimate of seismic horizontal $\mathrm{z}$ component signals for the interval of sol 1 through 552. The estimated standard error is $2.7 \mathrm{~dB}$. 


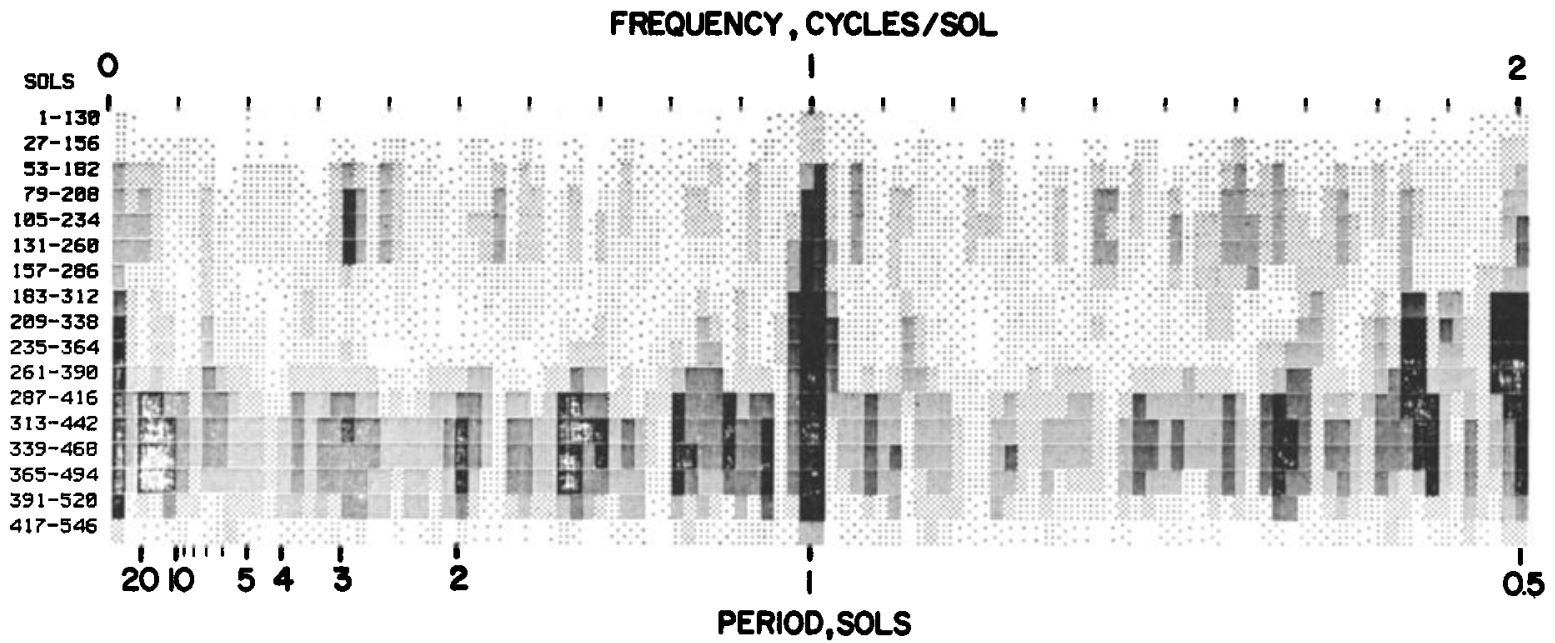

Fig. 6. Spectrogram of wind-induced seismic noise. The time interval covered is from sol 1 to sol 546 from top to bottom of the plot. Each step in shade corresponds to a difference in spectral density of $3 \mathrm{~dB}$. The linear trend with frequency has been removed.

spectral peaks occur at 2.0 and 3.7 sols. In the fall there are additional peaks at 1.8 and 2.5 sols. Other periodicitles are given in Table 1. Some of the peaks may simply represent harmonics of others. It should also be noted that many peaks are broad, possibly representing closely spaced multiple peaks. They may represent processes that are not exactly periodic but quasi-periodic。

Ryan et al. [1978] interpreted the regularity of the meteorology in terms of baroclinic waves of low wave number. Our results would indicate a wave number of 4 to 6 if the periodicities of 3 to 7 days are interpreted as single cycles and the period of 10-20 days is interpreted as a revolution of the whole pattern. This is

TABLE 1. Observed Spectral Peaks of Wind-Induced Seismlc Noise at Viking Lander-2 Site

\begin{tabular}{ccl}
\hline $\begin{array}{c}\text { Frequency, } \\
\text { cycles/sol }\end{array}$ & $\begin{array}{c}\text { Period, } \\
\text { sols }\end{array}$ & Remarks \\
\hline $\begin{array}{c}\text { 0.05-0.10 } \\
0.14\end{array}$ & $\begin{array}{c}10-20 \\
7\end{array}$ & longer period in fall \\
0.27 & 3.7 & winter-spring only \\
0.33 & 3.0 & \\
0.40 & 2.5 & fall only \\
0.50 & 2.0 & winter-spring on1y \\
0.56 & 1.8 & fall only \\
0.60 & 1.7 & \\
0.67 & 1.5 & \\
0.70 & 1.4 & \\
$0.82-0.95$ & $1.1-1.2$ & consists of several peaks \\
1.00 & 1.00 & \\
1.67 & 0.60 & \\
1.85 & 0.54 & \\
2.00 & 0.50 & \\
\hline
\end{tabular}

consistent with the wave numbers calculated by Ryan et a1. [1978].

Acknowledgements. We wish to thank G。V. Latham and H. J. Dorman for reviewing the manuscript and offering constructive comments. This work was supported by NASA contract NAS19703 and Grant NSG-7418. The University of Texas Marine Science Institute Contribution No. 338, Galveston Geophysics Laboratory. Contribution Number 3236, Division of Geological and Planetary Sciences, California Institute of Technology, Pasadena, California 91125.

\section{References}

Anderson, D. L., W. F. Miller, G. V. Latham, Y. Nakamura, M. N. Toksöz, A. M. Dainty, F. K. Duennebier, A. R. Lazarewicz, R. L. Kovach, and T. C. D. Knight, Selsmology on mars, J. Geophys. Res., 82, 4524-4546, 1977.

Cooley, J. W. , P. A. W. Lewis, and P. D. Welch, The fast Fourier transform algorfthm and its applications, Research Paper RC-1743, IBM Watson Research Center, Yorktown Heights, N. Y., 1967; also described in Kanasewich, E. R., Tline Sequence Analysis in Geophysics, The Univ. of Alberta Press, p. 95, 1973.

Hess, S. L。, R. M. Henry, C. B. Leovy, J. A. Ryan, and J. E. Tillman, Meteorological results from the surface of Mars: Viking 1 and 2, J. Geophys. Res., 82, 4559-4574, 1977.

Ryan, J. A., R. M. Henry, S. L. Hess, C. B. Leovy, J. E. TIllman, and C. Walcek, Mars meteorology; Three seasons at the surface, Geophys. Res. Letters, 5, 715-718, 1978 。

(Recelved Apri1 24, 1979; accepted May 8, 1979.) 